Çukurova Üniversitesi Mühendislik Mimarlık Fakültesi Dergisi, 32(3), ss. 197-204, Eylül 2017

Çukurova University Journal of the Faculty of Engineering and Architecture, 32(3), pp. 197-204, September 2017

\title{
Killi Zeminlerde Permeabilite ve Efektif Gerilmenin Kompaksiyon Enerjisine Bağlı Olarak Değişimi
}

\author{
Emre PINARCI ${ }^{* 1}$, Meltem TAŞÇI $^{1}$, Hasan ÇETIN $^{1}$

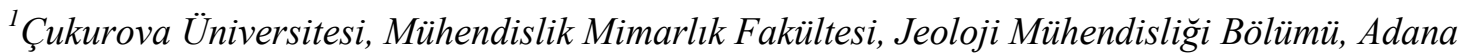

Geliş tarihi: 29.05.2017_ Kabul tarihi: 25.09 .2017

\begin{abstract}
Özet
$\mathrm{Bu}$ çalışmada kompaksiyonun önemli parametrelerinden biri olan sıkıştırma enerjisinin farklı oranlarda zemine uygulanması sonucu, zeminin mühendislik özelliklerinden permeabilite ve ön konsolidasyon basıncında $\left(\sigma_{\ddot{0} n}\right)$ meydana gelen değişiklikler araştırılmıştır. Çalışmada Atatürk Barajı kil çekirdeğinde kullanılan Sam-Tekin ariyet ocağından örselenmiş zemin numuneleri alınmıştır. Killi zemini sınıflamak için kıvam, tane boyu ve özgül ağırlık deneyleri yapılmışıtır. Standart Proctor deneyleri yapılarak zeminin farklı kompaksiyon enerjisinde $(15,25,35,45$ ve 55 vuruşlarda) maksimum kuru birim hacim ağılıkları ve optimum su içerikleri belirlenmiştir. Belirlenen bu maksimum kuru birim hacim ağırlık ve optimum su içeriği değerlerinde tekrar Standart Proctor deneyleri yapılmış ve konsolidasyon ringlerine numuneler alınarak permeabilite ve konsolidasyon deneyleri yapılmışıtır. Sonuç olarak zemine uygulanan kompaksiyon enerjisi arttıkça; zeminin kuru birim hacim ağırlığının arttığı, optimum su içeriğinin

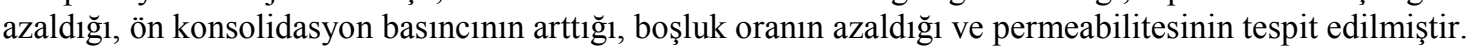

Anahtar Kelimeler: Kompaksiyon enerjisi, Permeabilite, Efektif gerilme

\section{Changes of Permeability and Effective Stress Compacted Clayey Soils Depending on the Compaction Energy}

\begin{abstract}
In this study changes in engineering parameters such as permeability and effective stress due to application of the compaction energy, one of the important parameters of compaction in different proportions have been investigated. Undisturbed clay samples obtained from the Sam-Tekin clay quarry, where the clay core material of the Ataturk Dam was taken, have been used in the study. In order to classify the samples, Atterberg Limits, grain size analysis and spesific gravity tests have been performed. The maximum dry unit weights and optimum moisture contents of compacted samples for 5 different compaction energies $(15,25,35,45,55$ blows $)$ have been determined by means of compaction tests. Permeability and consolidation tests have been performed on compaction samples taken from the compacted at the determined dry unit weights and optimum moisture contents. In conclusion, it was determined that as the higher the compaction energy increases, the dry unit weight and preconsolidation pressure increase and the optimum moisture content, void ratio and permeability decrease.
\end{abstract}

Keywords: Compaction energy, Permeability, Effective stress

*Sorumlu yazar (Corresponding author): Emre PINARCI, epinarci@cu.edu.tr 


\section{GíRiş}

Kompaksiyon genel olarak mekanik enerji uygulama yoluyla zeminin içerisindeki havanın uzaklaştırılmasıyla yoğunlaştırılması işlemidir [1]. Sıkıştırılmış zeminler türlerine ve sıkıştırma yöntemlerine göre farklı özellikler gösterir ve projelendirmelerde sıkıştırılmış zemin özellikleri önemli bir etkendir. Söz konusu özellikler permeabilite, şişme-büzülme, sıkışabilirlik, gerilme deformasyon ilişkisi ve kayma direncidir.

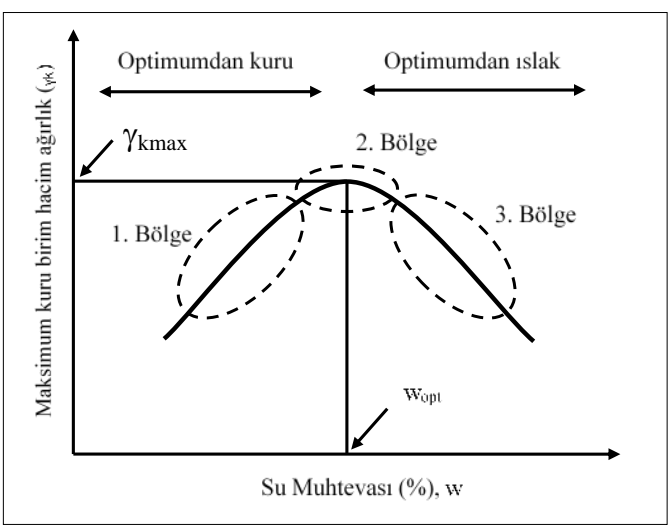

Şekil 1. Sıkıştırılmış bir zeminde $\gamma \mathrm{k}-\omega$ ilişkisi

Baraj ve bentler gibi su tutma yapılarında yer alan kil çekirdekler yapının en önemli kısmını oluşturmaktadır. Kil çekirdeğin gerekenden az enerji ile sıkıştırılması önemli mühendislik problemlerine yol açmaktadır. Laboratuvarda belirlenen maksimum kuru birim hacim ağırlığa $\left(\gamma_{\mathrm{k}}\right)$ arazide yetersiz sıkıştırma veya optimum su içeriğinden $\left(\omega_{\text {opt }}\right)$ farklı su içeriğinde sıkıştırma nedeniyle ulaşılamaması durumunda hedeflenen efektif gerilmelere ulaşılmayacağından ilerleyen zamanlarda baraj gövdesinde ciddi deformasyonların gözlenmesi kaçınılmazdır. Aynı şekilde yetersiz sıkıştırma sonucunda kil çekirdek olması gerekenden daha yüksek bir boşluk oranında olacak ve permeabilite problemleri yaşanacaktır. Zeminin permeabilitesi ile boşluk oranı arasında yaklaşık bağıntı göz önüne alınırsa, kuru birim hacim ağırlığın artması ile porozitenin azalması dolayısıyla permeabilitenin de azalması beklenir [2]. Kompaksiyon eğrileri optimumdan kuru, optimumda ve optimumdan islak olmak üzere üç kısma ayrılır (Şekil 1). Lambe [3] optimumdan kuruda sıkıştırılan zeminin su içeriği arttıkça permeabilitenin azaldığını, optimumda minimum olduğunu, optimumdan 1slakta bir miktar azaldığını daha sonra arttığını tespit etmiştir (Şekil 1). Zeminlerin ağır enerjilerde sıkıștırılması da kuru birim hacim ağırlıklarının artmasına ve boşlukların azalmasına yol açar. Optimumdan 1slakta ağır enerjide sıkıştırılan zeminlerin tane diziliminin paralel duruma geçmesiyle tanelere dik yönde permeabilitenin azalmasına karşın diğer yönde önemli bir değişiklik olmaz [2-5].

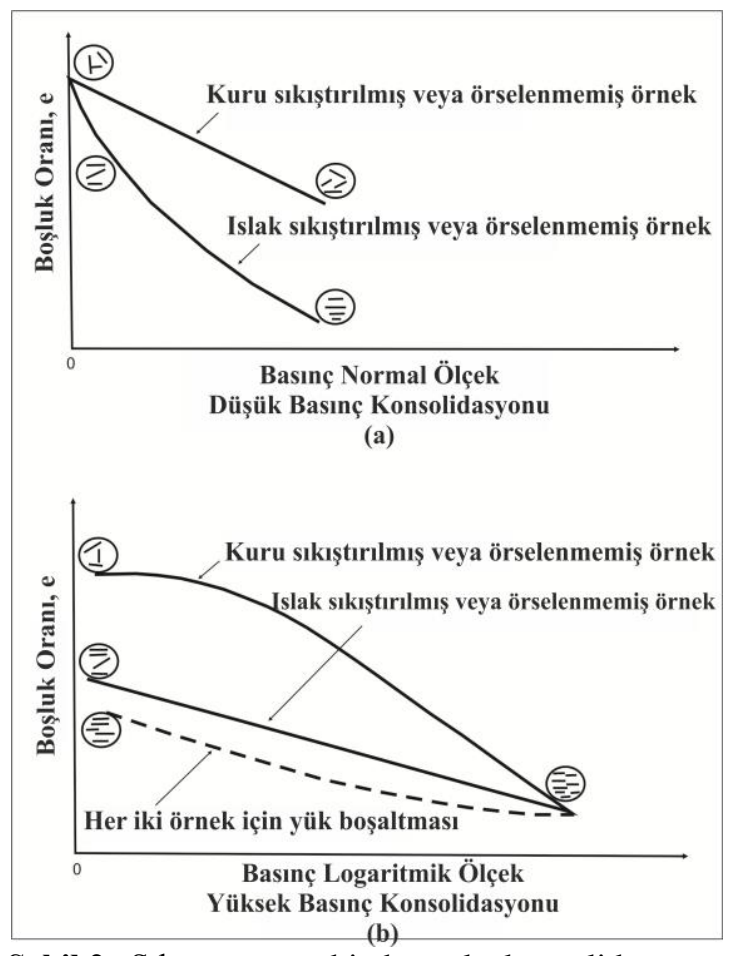

Şekil 2. Sikıştırmanın bir boyutlu konsolidasyona etkisi a) düşük basınçta b) yüksek basınçta [4]

Sıkıştırılmış kilde yapının ve su içeriğinin belirgin şekilde etkilendiği diğer bir özellik sıkışabilirliktir. Lambe [3], aynı birim hacim ağırlıkta optimumdan ıslakta sıkıştırılan kilin sıkışabilirliğinin optimumdan kuruda sıkıştırılan kilin sıkışabilirliğinden fazla olduğunu belirtmiştir. Şekil 2a'da düşük basınç altında optimumdan kuruda ve optimumdan ıslakta sıkıştırılmış kilin 
bir boyutlu konsolidasyon özelliği görülmektedir. Bunun karşıtı yüksek basınçlarda optimumdan kuruda sıkıştırılan kilin sıkışabilirliği optimumdan 1slakta sıkıştırılandan fazladır (Şekil 2b) [3].

Seed ve Chan [6] sıkıştırılmış killerin şişme büzülme özellikleri üzerinde yaptıkları çalışmada optimumdan kuru sıkıştırılmış killerde şişme potansiyelinin daha büyük olduğunu bulmuşlardır. Optimumdan kuru bölgede su açığı daha büyüktür ve dolayısıyla daha fazla su emme ve daha fazla şişme eğilimindedir. Optimumdan daha kuru zeminler, su içeriğindeki değişim gibi çevresel şartlara daha duyarlıdırlar. Optimumdan islak zeminlerde büzülme maksimumdur. Sıkıştırılmış killerin dayanım özellikleri oldukça karışıtır. Ancak optimumdan kuru sıkıştııılmış numunenin dayanımı optimumdan islak sıkıştırılmış numunenin dayanımından daha yüksektir. Optimumdan ıslak sıkıştırılmış numunenin dayanımı kompaksiyon yöntemine de bağlıdır. Bunun nedeni zemin yapısındaki farklılıktan ileri gelmektedir. Yoğrulmalı kompaksiyon ile sıkıştırılmış bir siltli kilin değişik sıkıştırma enerjilerinde elde edilen dayanım eğrileri Şekil 3'de verilmiştir. Bu eğrilerde üç değişik sıkıştırma enerjisi durumunda $\% 25$ birim deformasyon için gerekli gerilme ve $\% 5$ birim deformasyon için gerekli gerilme düzeyleri görülmektedir. Dayanımlar optimumdan islak durumlar için yaklaşık aynı iken optimumdan kuru durumlarda hafifçe artış göstermektedir. Optimumdan daha sslak su içeriğinde $\% 5$ birim deformasyon için gerekli gerilme düzeyi yüksek sıkıştırma enerjilerinde daha düşüktür [7]. Eğrilerin optimum kısımlarına bakıldığında ise kompaksiyon enerjisi arttıkça hem $\% 5$ birim deformasyon için gerekli gerilme hem de \%25 birim deformasyon için gerekli gerilme değerleri artış göstermiştir.

Bu çalışma ile farklı enerjilerde sıkıştırılan Atatürk barajında kullanılan kil çekirdek malzemesindeki efektif gerilme ve permeabilite değerlerinin ne ölçüde değiştiği buna bağlı olarak arazi sıkıştırmasının yetersiz yapılmasının bu önemli iki parametreyi ne ölçüde etkilediği tespit edilmeye çalışılmıştır.
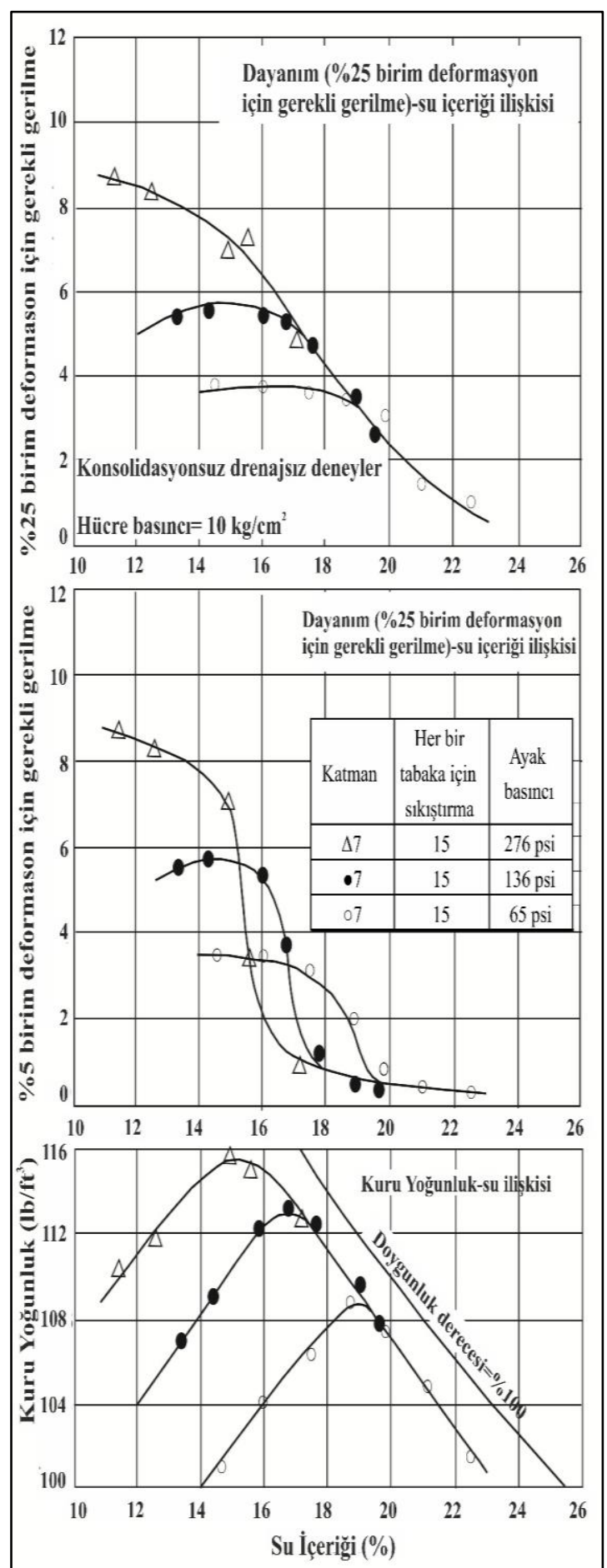

Şekil 3. Su içeriği ve sıkıştırma enerjisinin fonksiyonu olarak dayanım [6] 


\section{MATERYAL VE METOT}

\subsection{Materyal}

Bu çalışmada Şanlıurfa Bozova ilçesinde SamTekin kil ocağında bulunan killi zeminden alınan numuneler kullanılmıştır (Şekil 4).

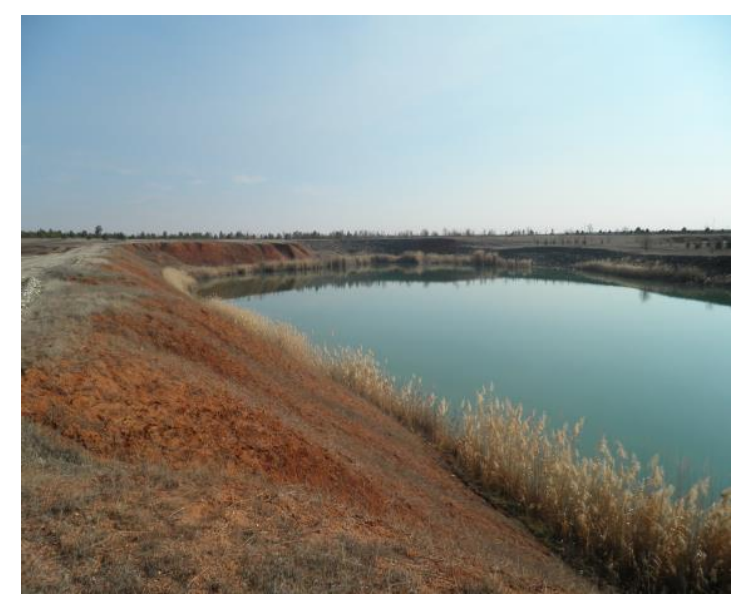

Şekil 4. Sam-Tekin ariyet ocağının görünümü

Zeminin indeks özelliklerinin belirlenmesinde standart laboratuvar araç ve gereçleri kullanılmıştır. Kompaksiyon karakteristiklerini belirlemek için yapılan Standart Proctor deneyinde 4" Proctor kalıb1 ve 2,5 kg'lık tokmak kullanılmıştır. Konsolidasyon deneyleri sabit halkalı ödometre cihazında yapılmıştır. Permeabilite deneyleri aynı ödometre cihazında düşen seviyeli permeabilite cihazı kullanılarak gerçekleştirilmiştir.

\subsection{Metot}

Ocaktan kıvam (Atterberg) limitleri, özgül ağırlık deneyi, tane boyu analizi ve kompaksiyon, konsolidasyon ve permeabilite deneylerinde kullanılmak üzere örselenmiş numuneler alınmıştır. Bu numuneler standartlara uygun olarak izole edilmiş ve taşımaya hazır hale getirilmiştir.

Killi zeminin indeks özelliklerini belirlemek için Atterberg (kıvam) limitleri deneyi, tane boyu (hidrometre ve elek) analizi ve özgül ağırlık deneyleri yapılmıştır.
Hesaplanan farklı kompaksiyon enerji değerleri (Çizelge 1) kullanılarak kompaksiyon deneyleri yapılmış olup, her bir enerji miktarı için kompaksiyon grafikleri çizilmiş ve bu grafiklerden maksimum kuru birim hacim ağırlık ve optimum su içeriği değerleri belirlenmiştir. Belirlenen bu değerlerde tekrar sıkıştırılan numuneler üzerinde, konsolidasyon ve konsolidasyon cihazında düşen seviyeli permeabilite deneyleri yapılmıştır.

Çizelge 1. Kullanılan vuruş sayıları ve kompaksiyon enerjileri

\begin{tabular}{|c|c|}
\hline $\begin{array}{c}\text { Vuruş } \\
\text { Sayısı }\end{array}$ & $\begin{array}{c}\text { Kompaksiyon Enerjisi } \\
(\mathbf{C E}) \\
\left(\mathbf{k J} / \mathbf{m}^{\mathbf{3}}\right)\end{array}$ \\
\hline 15 & 357,14 \\
\hline 25 & 595,24 \\
\hline 35 & 833,33 \\
\hline 45 & 1071,42 \\
\hline 55 & 1309,52 \\
\hline
\end{tabular}

\section{BULGULAR}

Zeminin sınıflaması için yapılan deneyler sonucunda bulunan değerler Çizelge 2.'de verilmiştir. $\mathrm{Bu}$ değerlere göre zeminin Birleştirilmiş Zemin Sınıflama Sistemi'ne (USCS) göre yüksek plastisiteli kil $(\mathrm{CH})$ olduğu belirlenmiştir.

Çizelge 2. Sınıflama deney sonuçları

\begin{tabular}{|l|c|}
\hline Likit Limit & $\% 62,4$ \\
\hline Plastik Limit & $\% 28,5$ \\
\hline Plasitisite İndisi & $\% 33,9$ \\
\hline Özgül Ağırlık & 2,65 \\
\hline Tane Boyu & \\
\hline Kil & $\% 47,0$ \\
\hline Silt & $\% 42,4$ \\
\hline Kum & $\% 10,6$ \\
\hline Çakıl & $\% 0$ \\
\hline
\end{tabular}


Zemine uygulanacak kompaksiyon enerjileri belirlenirken, standart olarak kullanılan 25 vuruşun altında ve üstünde değerler seçilmiştir. Zeminde meydana gelecek değişimlerin daha sağlıklı yorumlanabilmesi için kullanılacak enerjiler arasındaki farkın sabit bir değer olmasına dikkat edilmiş olup, iki enerji arasındaki fark $238 \mathrm{kj} / \mathrm{m}^{3}$ olarak seçilmiştir. En yüksek vuruş sayısı değeri kullanılan numunenin kil olmasindan ve fazla sıkışmadan dolayı çarpmalı kompaksiyonda tokmak sekmeleri oluşmasından dolayı 55 vuruş olarak sınırlandırılmıştır. Belirlenen kompaksiyon enerjilerinde numuneler sıkıștırılmış ve zeminin mühendislik özellikleri belirlenmiştir.

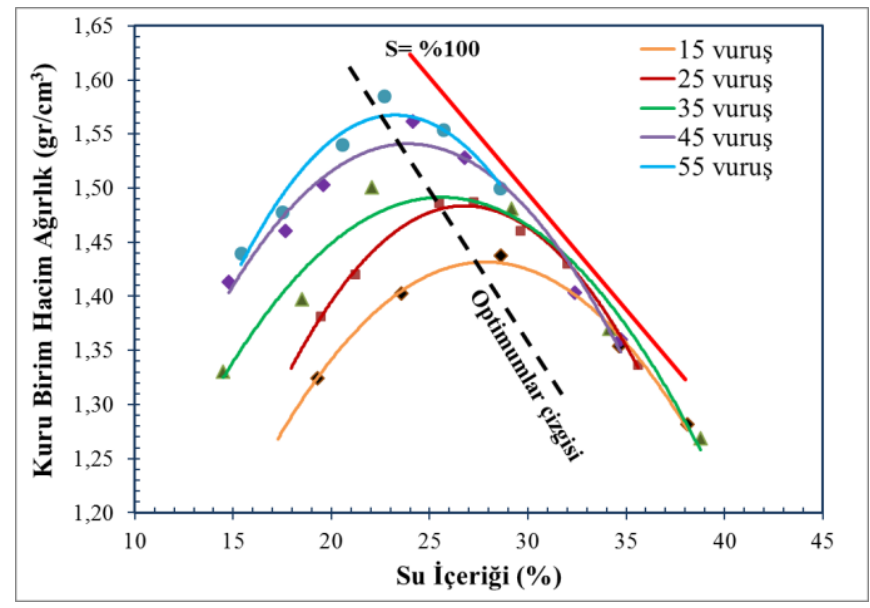

Şekil 5. Farklı enerjilerdeki kompaksiyon eğrileri

Şekil 5'deki grafikte kompaksiyon eğrileri yorumlanırken eğriler üç kısma ayrılarak her kısım kendi içinde değerlendirilmiştir.

Optimum bölgeleri incelendiğinde kompaksiyon enerjisi arttıkça eğrilerin pik noktalarının yükseldiği ve sola doğru kaydığ́ gözlenmektedir. $\mathrm{Bu}$ durum vuruş sayısı ve buna bağlı olarak kompaksiyon enerjisi arttıkça kuru birim hacim ağırlığın arttığını, buna karşın optimum su içeriğinin azaldığını göstermektedir.

Kuru birim hacim ağırlıkların enerji arttıkça birbirlerine göre artış miktarları yüzde olarak hesaplanmıştır. Bu hesaplamada 15 vuruşa karşılık gelen maksimum kuru birim hacim ağırlığa göre, diğer enerjilerdeki maksimum kuru birim hacim ağırlıkların artış miktarları sırasıyla \%3,23-\%5,59\%8,09-\%9,62 olarak bulunmuştur.

Optimum su içeriklerinin enerji arttıkça birbirlerine göre azalma miktarları yüzde olarak hesaplanmıştır. $\mathrm{Bu}$ hesaplamada 15 vuruş karşılık gelen optimum su içeriğine göre, diğer enerjilerdeki optimum su içeriği azalma miktarları sirasiyla \%4,13-\%7,36-\%13,46-\%16,05 olarak bulunmuştur.

Optimumlar çizgisi \%100 doygunluk çizgisine yaklaşık paralel konumdadır. $\mathrm{Bu}$ paralelliğin sebebi her ikisinde de kuru birim hacim ağırlığın artmasına karşın su içeriğinin düşmesidir. Hiçbir eğrinin \%100 doygunluk çizgisine değmediği gözlenmektedir. Bu durum kompaksiyon enerjisi ne kadar artarsa artsın zeminin hiçbir zaman \%100 doygunluğa ulaşmayacağını, zemin içerisinde daima bir miktar hava kalacağını göstermektedir.

Eğrilerin optimumdan kuru tarafları incelendiğinde eğri kollarının birbirine yaklaşık paralel olduğu gözlenmektedir. Kolların birbirine paralel olması enerjideki farkların gözle görülür boyutta olduğunu göstermektedir.

Dolgular sıkıştırılarak oluşturulmuş yapılardır. Buna rağmen zamanla dolguda gerek kendi ağırlıklarından gerekse üzerlerine yapılan 
yapilardan kaynaklanan oturmalar meydana gelebilir. Bu oturmanın mühendislik yapısına zarar vermemesi için belli sınırlarda kalması istenir. $\mathrm{Bu}$ nedenle dolguda meydana gelecek oturmanın hesaplanması gerekir. Bir zeminde meydana gelecek oturma konsolidasyon deneyi ile belirlenir. Ön konsolidasyon basincı ya da efektif gerilme $\left(\sigma_{\ddot{o}}\right)$ zeminde meydana gelecek oturmanın bir ölçüsüdür.

Farklı enerjilerde yapılan kompaksiyon deneylerinde elde edilen maksimum kuru birim hacim ağırlık ve buna karşılık gelen optimum su içeriğinde tekrar sıkıştırılan numuneler ile her enerji seviyesi için ikişer adet (toplam 10 adet) konsolidasyon deneyi yapılmıştır. Bu deneyler ile farklı sıkılıkta olan dolgu malzemelerinin gerilme koşullarındaki davranışları ve Casagrande [8] yöntemiyle de ön konsolidasyon basınçları belirlenmiştir (Şekil 6).

Şekil 6 ve Şekil 7'de görüldüğü gibi kompaksiyon enerjisinin artmasıyla zeminin boşluk oranı önemli ölçüde azalmış buna bağlı olarak oluşan efektif gerilmeler önemli derecede artmıştır (Çizelge 3)

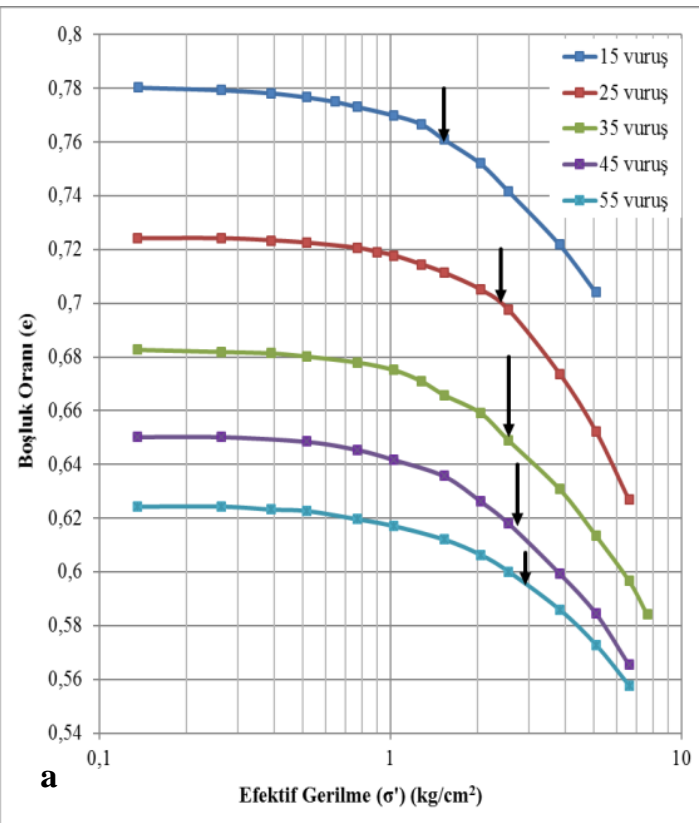

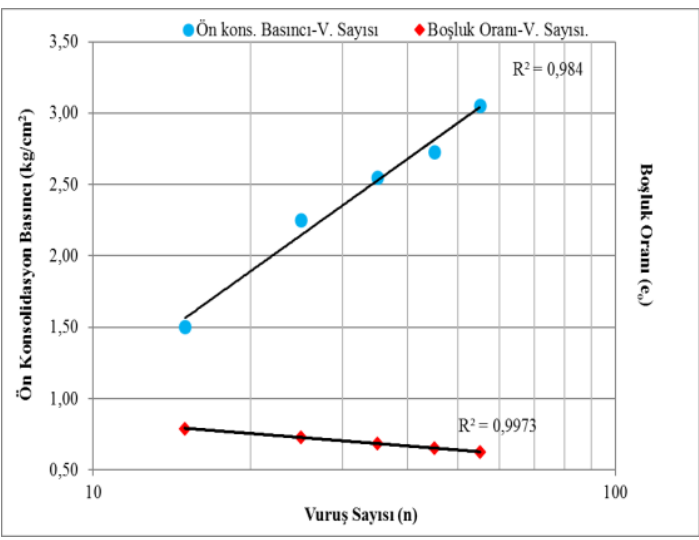

Şekil 7. Kompaksiyon enerjisi-efekti gerilme ve boşluk oranı ilişkisi

Çizelge 3. Farklı enerjilerde yapılan Proctor deneylerinden elde edilen ön konsolidasyon basınçları

\begin{tabular}{|c|c|c|c|c|c|}
\hline $\begin{array}{c}\text { Vuruş } \\
\text { Say1s1 }\end{array}$ & 15 & 25 & 35 & 45 & 55 \\
\hline $\begin{array}{c}\sigma_{\text {ön }} \\
\left(\mathrm{kg} / \mathrm{cm}^{2}\right)\end{array}$ & 1,51 & 2,25 & 2,56 & 2,73 & 3,06 \\
\hline
\end{tabular}

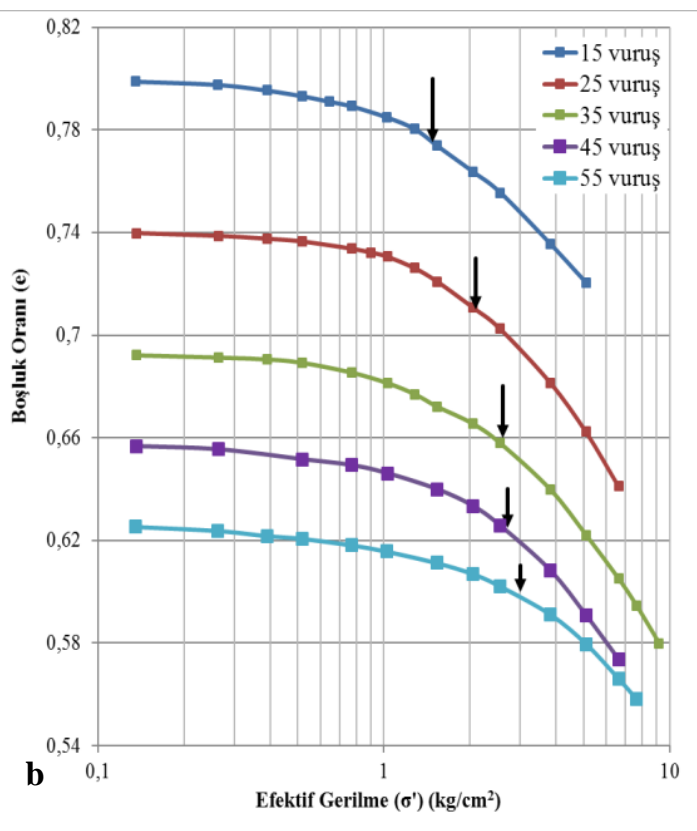

Şekil 6. Konsolidasyon deneyi sonucunda elde edilen boşluk oranı-efektif gerilme eğrileri a) 1. deney b) 2. deney 
Farklı oranlarda uygulanan kompaksiyon enerjileri sonucunda zeminde oluşan efektif gerilmeler standarttan düşük enerjiye göre (15 vuruş) kıyaslandığında 25 vuruşta ortalama \%49,01, 35 vuruşta $\% 69,85,45$ vuruşta $\% 81,43,55$ vuruşta $\% 103,20$ artış göstermiştir. Efektif gerilmedeki en büyük artışın standarttan düşük olan 15 vuruşta yapılan deney ile standart 25 vuruşluk deney arasında olduğu görülmüştür (Çizelge 4).

Çizelge 4. Farklı vuruş sayıları arasındaki efektif gerilmeler artışları $\left(\Delta \sigma_{\text {ön }}\right)$

\begin{tabular}{|l|l|l|l|l|}
\hline $\begin{array}{l}\text { Vuruş } \\
\text { Sayıları }\end{array}$ & $15-25$ & $25-35$ & $35-45$ & $45-55$ \\
\hline $\begin{array}{l}\Delta \sigma_{\text {ön }} \\
\left(\mathrm{kg} / \mathrm{cm}^{2}\right)\end{array}$ & 0,74 & 0,3 & 0,17 & 0,33 \\
\hline
\end{tabular}

Boşluk oranı ve efektif gerilmedeki bu değişim aynı şekilde zeminin permeabilite değerlerine de yansımıştır (Şekil 8). Kompaksiyon enerjisi arttıkça zeminin permeabilitesi beklendiği şekilde düşmüştür. 15 vuruşluk deneyden elde edilen permeabilite katsayısına göre diğer enerjilere karşılık gelen permeabilite değerlerinin azalış miktarları yüzde olarak hesaplanmış ve sırasıyla $\% 31,92, \% 55,01, \quad \% 69,47, \% 83,43$ olarak bulunmuş olup vuruş sayısına bağlı olarak enerji miktarı arttıkça permeabilite katsayılarının giderek azaldığı gözlenmiştir. Kompaksiyon enerjisi permeabilite katsayıları kullanılarak çizilen eğri incelendiğinde permeabilitedeki azalışın logaritmik olduğu gözlenmiştir. Eğrinin 55 vuruştan sonra $\left(1309,52 \mathrm{~kJ} / \mathrm{m}^{3}\right)$ asimptotik olduğu dolayısıyla bu enerji değerinden sonra permeabilite değerinin sabit kalacağı tespit edilmiştir.

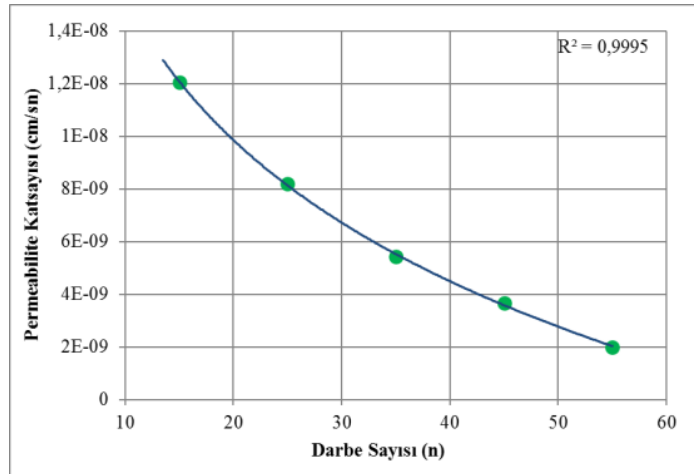

Şekil 8. Kompaksiyon enerjisi permeabilite ilişkisi

\section{SONUÇLAR}

Bu çalışmanın sonucunda; Standart Proctor deneyi sırasında optimumdan kuru bölgede kompaksiyon enerjisi arttıkça eğrilerin birbirine paralel optimumdan rslak bölgede ise eğrilerin birbirini kestiği görülmüştür. Bu durum optimumdan kuru bölgede enerji artışının gözle görülür etkisi olduğunu, optimumdan rslak bölgede ise enerji artışının boşlukların bir kısmının su ile dolmasından dolayı önemli bir etkisinin olmadığını göstermektedir.

\%100 doygunluk çizgisinin hiçbir eğriyi kesmediği yani kompaksiyon enerjisi ne kadar artsa da boşlukların tamamen su ile dolmadığı belirlenmiştir.

Konsolidasyon deneylerinde zemin Standart Proctor deneyinden (25 vuruş) elde edilen optimum su içeriği ve maksimum kuru birim hacim ağırlığa sıkıştırılmıştır ve elde edilen ön konsolidasyon basınçlarının artan enerji ile önemli ölçüde arttığ 1 gözlenmiştir. Standart enerjiden daha düşük enerji ile sıkıştırılan numunenin (15 vuruş) efektif gerilme değerinin $\% 48,9$ daha düşük elde edildiği tespit edilmiştir.

Standart Proctor enerjisi ile sıkıştırılan zemin üzerine yapılan permeabilite deneylerinde azalan boşluk oranı ile zeminin permeabilitesinde ciddi azalışlar gözlenmiştir. 45 ve 55 vuruşta yapılan deneylerden sonra zeminin permeabilitesindeki azalımın yavaşladığı gözlenmiştir. Standart Proctor enerjisinden daha düşük enerjide yapılan (15 vuruş) deneyde permeabilite değerinin \%34,8 daha düşük bir değer olduğu belirlenmiştir.

$\mathrm{Bu}$ veriler 1şığında arazide sıkıştırma yaparken ekipmanların verimsizliği, personelin yeterli deneyime sahip olmaması gibi nedenlerle sıkıştırmanın yeterli miktarda yapılmamasının zeminin permeabilitesi ve efektif gerilmesi üzerinde önemli etkilerinin olacağı tespit edilmiştir. Beklenenden daha düşük efektif gerileme ve permeabiliteye sahip olan kil çekirdek dolgularının stabilitesi üzerinde olumsuz etkilere neden olması kaçınılmaz olduğundan sıkıştırma 
enerjisinin doğru uygulanmasına azami dikkat gösterilmesi gerektiği ortaya çıkmaktadır.
Mechanics and Foundation Engineering, Cambridge, Vol. 3 60-64.

\section{TEŞEKKÜR}

$\mathrm{Bu}$ çalışma Çukurova Üniversitesi Bilimsel Araştırma Projeleri Birimi tarafından desteklenmiştir (Proje No: MMF2010YL19).

\section{KAYNAKLAR}

1. Das, B., M., 2010. Principles of Geotechnical Engineering, $7^{\text {th }}$ Edition. Cengage Learning 200 First Stamford Place, Suite 400 Stamford, CT 06902 USA.

2. Lambe, T.W., 1958a. The Structure of Compacted Clay. Journal of the Soil Mechanics and Foundations Division, Proceedings of the American Society of Civil Engineers, Paper 1654, Vol. 84, No. SM 2, $1-34$.

3. Lambe, T.W., 1962. Soil Stabilization, Chapter 4 of Foundation Engineering, G.A. Leonards (ed) Mc. Graw-Hill, New York.

4. Lambe, T.W., 1958b. The Engineering Behavior of Compacted Clay. Journal of the Soil Mechanics and Foundations Division, Proceedings of the American Society of Civil Engineers, Paper 1655, Vol. 84, No. SM 2, 1-34.

5. Cetin, H., Fener, M., Soylemez, M., Gunaydın, O., 2007. Soil Structure Changes During Compaction of a Cohesive Soil. Engineering Geology 92, 38-48.

6. Seed, H.B., Chan, C.K., 1959. Structure and Strength Characteristics of Compacted Clays. Journal of the Soil Mechanics and Foundations Division, Proceedings of the American Society of Civil Engineers, Vol. 85, No. SM 5, 87-128.

7. Holtz, R.D., Kovacs, W.D., 1981. (Çeviri: Kayabalı, K., 2002). Geoteknik Mühendisliğine Giriş, Gazi Kitabevi, Ankara 723. III. 60-64.

8. Casagrande, A., 1936. The Determination of the Pre-Consolidation Load and its Practical Significance, Discussion D-34, Proceedings of the First International Conference on Soil 